\title{
LA DETERMINACIÓN DE LA EDAD DE LOS EXTRANJEROS INDOCUMENTADOS
}

\author{
POR \\ ANA RUIZ LEGAZPI \\ Investigadora de Derecho Constitucional \\ Universidad de Valladolid
}




\section{SUMARIO}

I.- INTRODUCCIÓN. II.- LOS MENORES EXTRANJEROS: 1.- Concepto de menor extranjero. 2.- La situación jurídica del extranjero de edad desconocida. 3.- La prohibición de expulsión de menores. III.- EL PROCEDIMIENTO DE DETERMINACIÓN DE LA EDAD: 1.- Los problemas de competencia para determinar la edad. 2.- Las pruebas de determinación de la edad y los derechos fundamentales del extranjero indocumentado. 3.- La autorización judicial de las pruebas para determinar la edad. 4.- Sobre el papel del Ministerio Fiscal en el procedimiento para determinar la edad. IV.- LA DETERMiNACIÓN DE LA EDAD Y LA LIBERTAD PERSONAL: 1.- La privación de libertad policial. 2.- La privación de libertad judicializada. V.- LOS RECURSOS CONTRA LA DETERMINACIÓN DE LA EDAD. 


\title{
LA DETERMINACIÓN DE LA EDAD DE LOS EXTRANJEROS INDOCUMENTADOS
}

\author{
POR \\ ANA RUIZ LEGAZPI \\ Investigadora de Derecho Constitucional \\ Universidad de Valladolid
}

\section{INTRODUCCIÓN}

La determinación de la edad de los extranjeros indocumentados es un aspecto de especial interés dentro del fenómeno de la inmigración irregular y de los menores inmigrantes.

Desde hace algún tiempo se ha constatado, no sin preocupación, el aumento de la inmigración infantil, es decir, de aquella protagonizada por jóvenes extranjeros que, aun siendo menores de edad, emprenden un proyecto migratorio propio e independiente de sus familias. En nuestro entorno cultural se les conoce como menores extranjeros no acompañados ${ }^{1}$.

${ }^{1}$ Se adopta la definición del art. 1 de la Resolución del Consejo de Europa de 26 de junio de 1997, DOCE de 19 de julio de 1997, C 221, p. 23 a 26. Junto a ésta, a menudo se utilizan otras expresiones de significado similar como, por ejemplo, menores separados. Vid. ACNUR, Separated Children in Europe Program. Statement of good practice, enero 1999. 
Los problemas derivados de esta peculiar inmigración se han de colocar en el centro del debate político-jurídico sobre esta nueva realidad social, como han puesto de manifiesto ciertas medidas de política migratoria adoptadas contra algunos de estos jóvenes y a las que tendremos ocasión de referirnos.

A la hora de abordar el problema que nos ocupa, es importante aclarar desde este momento que el régimen jurídico que se aplica a la situación de irregularidad es diferente en función de la edad del extranjero. El régimen de los extranjeros menores ha de estar inspirado en el principio de protección del interés superior del menor ${ }^{2}$, que impide su expulsión del territorio, sanción en la que, por otra parte, se concreta el tratamiento jurídico que de ordinario se brinda al extranjero irregular cuando es adulto. La idea es que la cláusula social del Estado de Derecho ha consagrado un tratamiento universal de protección a la infancia que ha de desplazar, en el ámbito de la extranjería, a cualquier tratamiento normativo basado en el control de los flujos migratorios.

Para dar respuesta a este objetivo, el artículo 35 de la Ley de Extranjería ${ }^{3}$ prevé dos posibles soluciones para el fenómeno de la inmigración infantil. La primera consiste en la repatriación del menor para reagruparlo con su familia $y$, sólo cuando esto no sea posible, como segunda $y$ última alternativa, se permite la residencia del menor en España, que sería regular hasta que adquiriera la mayoría de edad.

En definitiva, mediante este trato específico se pretende enervar la solución general prevista por la legislación para aquellos extranjeros que no son menores y que consiste, con carácter general, en la expulsión del territorio.

En este contexto, la edad, más en concreto, la mayoría o minoría de edad, condiciona la aplicación de un régimen jurídico u otro. Como consecuencia de las expectativas que genera el régimen de los menores extranjeros, sobre todo en la medida que se considere prohibida su expulsión, es lógico sospechar que existan personas que aleguen ser menores cuando en realidad no lo son, para, de esta manera, huir de la aplicación del régi-

2 Sobre todo arts. 2.1 y 3.1 de la Convención de Derechos del Niño, ratificada por España e indirectamente constitucionalizada en virtud del Art. 39.4 CE. Toda la legislación, tanto nacional como autonómica, de protección del menor se desarrolla con una clara inspiración en este principio.

${ }^{3}$ Ley $4 / 2000$, de 11 de enero, de Derechos y Libertades de los Extranjeros en España y su Integración Social, reformada sucesivamente por la Ley $8 / 2000$, de 22 de diciembre $Y$ por la Ley 14/2003, de 20 de noviembre, (en adelante LE o Ley de Extranjería). 
men general de extranjería, de marcado cariz sancionador. Cuando no se pueda comprobar la verdadera edad del extranjero porque carece de documentos o porque los que posee son falsos, se impone arbitrar instrumentos que permitan determinar la edad y delimitar así el régimen jurídico que deviene aplicable.

El legislador en materia de extranjería se ocupa de este problema especial en el primer párrafo del artículo 35, a través de la instauración de una suerte de procedimiento que presenta serias contradicciones y lagunas, tal como se va a intentar resumir en este trabajo.

En primer lugar se atenderá a la definición de menor extranjero y la situación en la que se encuentra en tanto se determina su edad, con una necesaria reflexión en torno a su prohibición de expulsión (II). No obstante, los problemas centrales se refieren a los métodos empleados para determinar la edad de estas personas que, como se dirá, pueden afectar a derechos fundamentales. Este aspecto pone en entredicho la intervención del Ministerio Fiscal exigida en la Ley y exige la participación de un juez a la que no alude el legislador (III). Tampoco se puede pasar por alto la situación de privación de libertad que sufre quien se ve afectado por este procedimiento (IV). Finalmente, la determinación de la edad plantea tantos problemas que hay que preguntarse qué puede hacer un extranjero cuya edad ha sido estimada de forma errónea en su perjuicio (V).

\section{LOS MENORES EXTRANJEROS.}

\section{Concepto de menor extranjero.}

La mayoria de edad es un concepto juridico definido en cada ordenamiento. En el nuestro, es necesario acudir al artículo 9.1 del Código Civil (CC), que contiene una norma de Derecho internacional privado, según la cual la ley personal determinada por la nacionalidad es la que rige la capacidad y el estado civil de las personas. Como es fácil adivinar, esta remisión a las legislaciones nacionales de los menores extranjeros plantea serios problemas de eficacia, pues la aplicación del Derecho extranjero está sujeta a un proceso de prueba de vigencia y contenido que no siempre se puede realizar y parte de unas premisas que no se ajustan a la realidad de la inmigración, pues la nacionalidad del inmigrante no se conoce siempre. En la práctica, estas dificultades se han sorteado estableciendo el límite de la minoría de edad en los 18 años, tal como hace la norma española en los artículos 12 de la Constitución y 315 del CC, con independencia de lo que dispongan las respectivas legislaciones nacionales. 
Hay razones jurídicas que pueden avalar esta práctica, sin embargo. La aplicación de leyes distintas a un mismo supuesto de hecho, la adquisición de la mayoría de edad, podría tener efectos discriminatorios en el disfrute del estatuto de protección de los menores, que es una de las normas imperativas de orden público de nuestro ordenamiento ${ }^{4}$, al consagrar valores como la protección a la infancia y el interés del menor, que son esenciales en nuestro sistema constitucional ${ }^{5}$.

Al tratarse de una norma de tal entidad, no es posible introducir diferencias de esta naturaleza en su disfrute, pues las diferenciaciones por razón de la nacionalidad entrañan discriminaciones proscritas en nuestra Constitución ${ }^{6}$. De suerte que, para garantizar la eficacia del estatuto de protección de los menores sin discriminaciones, resulta imprescindible una solución jurídica única para la adquisición de la mayoría de edad que se aplique a todos los menores que se encuentren en España. Por razones obvias, esta norma será la ley española que fija en 18 años la adquisición de la mayoría de edad, respetando las disposiciones internacionales en la materia (artículo 1 de la Convención de Naciones Unidas de Derechos del niño, en adelante CDN).

Algunos autores llegan a conclusiones similares, sin tener que invocar la fuerza imperativa de las normas de protección de los menores, en combinación con los artículos 13.1 y 14 de la Constitución. Así, se defiende que la Ley de Extranjería contiene implícitamente un concepto propio de menor, que englobaría a todos los extranjeros con menos de 18 años que se encuentren en territorio nacional?.

En el Derecho comunitario, por su parte, el Consejo engloba, dentro del ámbito de aplicación de la Resolución relativa a menores no acompa-

${ }^{4}$ STC 141/2000, de 29 de mayo, Fdto. Jco. $5 .^{\circ}$

${ }^{5}$ ESPINAR VICENTE, J. M. ${ }^{a}$, "La protección del menor extranjero en el sistema jurídico español", Infancia y Sociedad, n. ${ }^{\circ} 33,1995$, p. 85. Del mismo autor, Teoría General del Derecho Internacional Privado, Madrid, 2000, p. 93 y 169.

${ }^{6}$ Según la jurisprudencia del Tribunal Constitucional, los derechos de los menores, al ser indisponibles para los poderes públicos se encuadrarian, dentro de la tradicional clasificación tripartita de los derechos de los extranjeros, entre aquellos que les corresponden en igualdad con los españoles. (STC 141/2000, cit. en relación con STC 107/1984, 23 de noviembre, por todas). Sobre los extranjeros $y$ el derecho de igualdad, vid. Vidal Fueyo, C., Constitución y extranjeria, Madrid, 2002, p. 159 y ss.

7 Esteban DE LA Rosa, G., Comentarios Sistemáticos a la Ley de Extranjería, Moya Escudero, M. (coord.), Granada, 2001, p. 135 y Moliner Navarro, R.M., "Reagrupación Familiar y modelo de familiar en la LO $8 / 2000$ de Derechos y Libertades de los Extranjeros en Españan, Actualidad Civil, n 14, abril, 2001, p. 508. 
ñados, a todos los menores de 18 años. Además, estas interpretaciones respetan la recomendación del Parlamento Europeo según la cual, conceptos como el de mayoría de edad, que se mencionan con frecuencia en la legislación nacional, deben utilizarse siempre en interés del niño ${ }^{8}$.

\section{La situación jurídica del menor extranjero de edad desconocida.}

La situación en la que se encuentra un extranjero, de cuya minoría de. edad se duda, en tanto se comprueba si tiene los años suficientes para adquirir la mayoría de edad, es un tanto dudosa. Como premisa de partida, se puede deducir de la regulación general un principio de presunción iuris tantum de minoridad, en virtud del cual, mientras no se demuestre lo contrario, el joven es considerado menor y ha de ser tratado como si lo fuera. La razón es que la única forma de garantizar la adecuada protección, si resultara ser menor, es tratarlo como si lo fuera mientras se comprueba este extremo. El problema surge a la hora de definir en qué consiste este trato.

De acuerdo con la remisión a la legislación de protección de menores del artículo $35.1 \mathrm{LE}$, como presunto menor no acompañado, el joven se encuentra en una situación de desamparo, tal como se define en el artículo $172.1 \mathrm{del}$ CC. Lo que resulta decisivo de esta situación es que, desde el mismo momento en que se constata el supuesto de hecho genera, de. forma automática, por disposición de la ley y sin necesidad de declaración formal alguna, la tutela administrativa a cargo de los servicios de protección de menores, según lo dispuesto en el primer párrafo del artículo anterior y en el 18 de la Ley de Protección Jurídica del Menor (LPJM) ${ }^{9}$. Y resulta determinante porque esta tutela administrativa permite dotar de. ciertos visos de legalidad, al menos por el momento, a la estancia del extranjero en España ${ }^{10}$, impidiendo su expulsión inmediata del territorio, que es lo que a la postre importa.

Sin embargo, es honesto advertir que esta interpretación plantea problemas, derivados de que su inclusión en el tenor literal del artículo 35

${ }^{8}$ Apartado P de la Resolución del Parlamento Europeo de 12 de diciembre de 1996, DOCE de 20 de enero de 1997, C20, p. 170 a 176.

9 Vid. entre otros, Martínez CANO-Cortés, Y., "Artículo 32" en Comentarios a la nueva Ley de Extranjería, SANTOLAYA MACHETtI, P. (coord.), Valladolid, 2000, p. 191; Alonso PÉrez, F., Régimen Jurídico del Extranjero en España, Madrid, 2002, p. 269; ACNUR, Separated Children in Europe..., op. cit., C.5 y Apartado C. b) de las Conclusiones del XII Encuentro de Abogados sobre Derecho de Extranjeria, Alicante, mayo, 2002.

${ }^{10}$ Art. 35.4 LE. 
de Ley de Extranjería es discutible. Asi es si tenemos en cuenta que, este precepto, tras referirse a la determinación de la edad, sólo contempla la puesta a disposición de los servicios de protección de menores una vez que se haya confirmado la minoria, en su apartado segundo. Es decir, parece que pospone la asunción de la tutela al momento en que se haya confirmado que el joven es menor.

Además, hay que tener presente que, la asunción de la tutela administrativa durante la fase de determinación de la edad, implica una lectura un tanto forzada de la institución, con una finalidad distinta de aquella para la que fue creada ya que, ahora, más que una salvaguarda eficaz, se persigue evitar una expulsión.

Justo por esta razón, a pesar de las dificultades, es necesario defender la eficacia de la tutela administrativa pues, siempre de acuerdo con el interés del menor, constituye un argumento jurídico de primer orden frente a la expulsión inmediata de estos jóvenes ${ }^{11}$.

\section{La prohibición de expulsión de menores.}

La gran diferencia entre el régimen de extranjería general y el de los menores es su posición frente a la expulsión del territorio ${ }^{12}$. Esta sanción, con la que de forma ordinaria se sanciona la irregularidad en la que incurre un extranjero (art. 57.1 LE), deviene inaplicable cuando éste es menor de edad. El problema reside en que, en la actualidad, no existe una norma jurídica que de forma expresa prohíba la expulsión en estos casos ${ }^{13}$.

${ }^{11}$ Es curioso observar como en Francia se defiende una interpretación de la normativa de protección similar a la mayoritaria en España. La situación de los menores extranjeros que llegan a las fronteras solos y sin representante legal es, técnicamente, una situación de peligro definida en el artículo 375 del Código Civil francés. En estos casos, la legislación francesa de protección social exige la protección administrativa del menor (art. 223-2 del Code de l'action sociale et des families). Vid. Creoff, M., "Qu'este ce que qu' enfant en danger?", Plein Droit, n. ${ }^{\circ}$ 52, 2002, p. 7 y ss.

12 Como consideración preliminar es necesario advertir que, al hablar de expulsión, se está haciendo referencia a todas las medidas de alejamiento del territorio español inspiradas en el control de flujos migratorios y de sanción de la inmigración irregular. Se excluye, por tanto, la medida de repatriación que prevé el propio artículo 35 porque responde, al menos en teoría, a una filosofía distinta, la del interés del menor en reagruparse con su familia.

${ }^{13}$ A diferencia de la prohibición expresa prevista, durante la vigencia del régimen de extranjería anterior, en el artículo 13 del Reglamento de ejecución de la Ley 7/1985, de 1 de julio, sobre Derechos y Libertades de los Extranjeros en España, aprobado por RD 155/1996, de 2 de febrero. 
En general, la laguna es interpretada de forma casi unánime a favor de la prohibición de expulsión del menor, de acuerdo con el mandato constitucional de protección a la infancia. En este sentido, se advierte que resulta imposible acordar la expulsión de un menor sin vulnerar alguna de las normas que integran su estatuto de protección, de inexcusable observancia para todos los poderes públicos. Entre las normas que ser verían afectadas podemos citar el artículo $39 \mathrm{CE}$ o la Convención de Derechos del Niño, sin olvidar el Convenio Europeo de Derechos Humanos o la Resolución Europea relativa a la Carta de los Derechos del Niño ${ }^{14}$. Por no insistir en que la regulación del régimen de menores del artículo 35 no tendría sentido si el legislador hubiera contemplado la posibilidad de que estos jóvenes fueran expulsados, pues hubiera sido suficiente con remitirse al régimen general.

No obstante, se ha defendido, hasta ahora de forma minoritaria, la legalidad de la expulsión de menores. Se han aducido razones materiales, como la insuficiencia de recursos para ocuparse de todos los menores extranjeros que se quedarian en España si, aun habiendo entrado de forma irregular, no pudieran ser expulsados ${ }^{15}$. También se esgrimen razones de mera legalidad, como que la Ley de Extranjería no contempla entre las causas que impiden la expulsión ser menor no acompañado ${ }^{16}$.

Pero la postura más polémica defendiendo la expulsión de estos menores la ha sostenido el Fiscal General del Estado en su Instrucción $3 / 2003$, de 23 de octubre, sobre la procedencia del retorno de los extranjeros menores de edad que pretendan entrar ilegalmente en España y en quienes no concurra la situación jurídica del desamparo. Como pone de manifiesto su ilustrativo título, la intención de la Instrucción no es otra que la de justificar la expulsión de los jóvenes mayores de 16 años. Para ello se ve obligada a negar que padezcan una situación de desamparo generadora de una obligación legal de tutelarlos.

Antes que nada, conviene recordar que la Fiscalía General del Estado había sido tajante al reconocer la prohibición de expulsión de los menores

14 FÁBrega RuIz, C.F., La protección jurídica del menor inmigrante, Madrid, 2001, p. 94. Así lo recuerda también Human Rigths Watch España y Marruecos, Callejón sin salida: abusos cometidos por las autoridades españolas y marroquíes contra niños inmigrantes, Human Rigths Watch España y Marruecos, 2002, en <www.hrw.org>. 1999 , p. 86.

15 Hidalgo Baras, l., "Inmigración ilegal», Revista del Ministerio Fiscal, n. ${ }^{\circ} 6$,

${ }^{16}$ LOPEZ LOPEZ, A., “Inmigración, delincuencia y minoría de edad» en La instrucción del Ministerio Fiscal en el procedimiento de menores, Granada, 2002, p. 375. 
en situación de desamparo ${ }^{17}$. Por esta razón, para no contradecirse, ahora debe reinterpretar este concepto jurídico, aunque para ello deba hacer encaje de bolillos y defender una lectura incompatible con el que proclaman la Convención de Derechos del Niño y la Ley de Protección Jurídica del Menor ${ }^{18}$.

En la Instrucción se sigue reconociendo que la protección contra la expulsión la brinda la situación de desamparo del menor, pero se matiza indicando que esto no significa que todos los menores extranjeros que se encuentran en España estén legalmente desamparados. En concreto, se presume que aquellos extranjeros de más de 16 años no lo están, pues aun concurriendo en ellos un elemento de carácter subjetivo, como puede ser la ausencia de asistencia moral, falta en estos casos otra condición que ha de cumplirse acumulativamente (aunque la definición legal no lo exija), que se refiere a la falta de asistencia material. En propiedad, afirma la Fiscalía, estos menores no carecen de medios para vivir pues habitualmente realizan actividades remuneradas (aunque no añade que con los riesgos de la explotación laboral, al no tener permiso para trabajar de forma legal en España). Así, se presume que los jóvenes de más de 16 años tienen, en realidad, una vida independiente consentida por sus padres $y$ familiares, razón por la cual han de considerarse emancipados y ser tratados, no como menores, sino como personas con capacidad para regir sus bienes y persona (de acuerdo con los artículos 319 y 323 del CC).

Esta postura plantea serios problemas de legalidad, incluso de constitucionalidad. Tratándose de menores, en nuestro ordenamiento, se impone la interpretación de las normas inspirada en el superior interés del menor, de acuerdo con el mandato constitucional de protección de la infancia. Asi, considerar emancipado al inmigrante mayor de 16 años, porque vive de forma independiente con el consentimiento de sus padres, representa una lectura de la emancipación, además de forzada, pues no se creó para el fenómeno de la inmigración infantil, perjudicial para el interés del menor, si permite que sea inmediatamente expulsado del territorio. Por su parte, la reinterpretación de la situación de desamparo plantea el problema de su carácter restrictivo, pues exige que se den de forma concurrente dos requisitos cuando la ley no lo hace. Pero, además, tiene un carácter discriminatorio porque, en el fondo, admite un concepto especial de desamparo de los inmigrantes que, desde luego, no

17 Instrucción 2/2001, de 28 de junio, en relación con la interpretación de la Ley $4 / 2000$ y Circular 3/2001, de 21 de diciembre, sobre la actuación del Ministerio Fiscal en materia de extranjería.

${ }^{18}$ Pantoja García, F., "Menores inmigrantes», El País, 13 de noviembre de 2003. 
serviría cuando se trate de un español, toda vez que las normas de protección de menores deben aplicarse sin discriminación alguna por razón de nacionalidad, como prescribe el artículo 2. 1 CDN.

En efecto, esta Instrucción ha recibido severas críticas de la doctrina y de los agentes sociales, a consecuencia de las cuales el Defensor del Pueblo ha intervenido solicitando la retirada de la misma. Aunque el efecto deseado no se ha producido, pues el Fiscal General se ha reafirmado en su postura, al menos se ha mostrado dispuesto a dejar sin efecto total o parcialmente la citada Instrucción, si el interés del menor lo aconsejara en el futuro inmediato ${ }^{19}$. En este sentido, ha anunciado la aprobación en los próximos meses de una Circular más amplia sobre inmigración, destacando que la Instrucción a la que nos venimos refiriendo será provisional ${ }^{20}$.

Sin embargo, el efecto más grave que ha generado ha sido abrir las puertas de una política sancionadora de la inmigración infantil, rompiendo los pilares del sistema de protección de menores. Así lo demuestra que, al poco tiempo de conocerse la Instrucción, el Ministerio del Interior anunciara la adopción de un nuevo procedimiento de repatriación de menores, que se ha concretado en el Memorandum de entendimiento entre el Reino de España y Marruecos sobre la repatriación asistida de menores no acompañados, de 23 de diciembre de 2003.

En teoría, la finalidad de este acuerdo no es la expulsión de los menores, sino establecer un cauce para su repatriación y reagrupación con su familia, de acuerdo con lo dispuesto en el artículo $35 L^{21}$. Ocurre que, en realidad, la reglamentación se acomete de un modo tal que viene a dar cabida no ya a las expulsiones, sino también a las devoluciones y retornos

19 Diario de Noticias La Ley, 24 de diciembre de 2003

20 De este modo se ha secundado la tendencia de otros países, como Francia e Italia, donde han existido intentos de flexibilizar el régimen de los menores de más de 16 años con la intención de posibilitar su expulsión o retorno. El Gobierno italiano presentó un proyecto de ley, Dd-I de 20 de marzo de 1997, n. ${ }^{\circ} 60$, finalmente rechazado por el Parlamento, en el que se establecía que los extranjeros podían ser expulsados del territorio siempre que fueran mayores de 16 años. De la misma manera, la prensa francesa se hizo eco de un proyecto de reforma legal mediante el que se pretendia introducir una diferenciación en la capacidad jurídica de las personas a los dieciséis años para poder expulsar legalmente a los extranjeros que superaran esta edad. Vid. Le Monde, 8 de julio de 2000 , "Le gouvernement prépare un projet de loi limitant la protection des mineurs étrangers».

${ }^{21}$ En efecto, la Ley prevé con carácter preferente, dentro del régimen de menores, la repatriación con la finalidad de reagruparlos con sus familias y, sólo cuando esto no es posible, contempla su residencia en España. La doctrina ha criticado la inmediata identificación a priori de la repatriación y reagrupación familiar con el interés del menor 
de los menores inmigrantes marroquíes, que son simples medidas de control de los flujos migratorios que nada tienen que ver con la reagrupación del menor con su familia.

\section{EL PROCEDIMIENTO DE DETERMINACIÓN DE LA EDAD.}

\section{Los problemas de competencia para determinar la edad.}

El artículo 35.1 LE se refiere a la determinación de la edad del extranjero que se cree puede ser menor, como es sabido. Sin embargo, no aclara quién determina la edad, ni cómo se determina, ni cuál es la función del Ministerio Fiscal, ni el procedimiento a seguir, ni tampoco la naturaleza de las actuaciones que se deben llevar a cabo. Por estas razones, la doctrina critica la regulación legal $y$ denuncia el constante esfuerzo de interpretación jurídica que requiere.

La determinación de la edad, tal como la prevé el legislador, sólo adquiere pleno sentido jurídico si se pone en relación con las demás previsiones contenidas en el mismo artículo. En efecto, a lo largo de los apartados siguientes se instaura el régimen jurídico-administrativo de los extranjeros menores de edad que se encuentren en nuestro territorio. Es decir, se puede afirmar que, en él, se regula el estatuto especifico del menor extranjero que se encuentra en España, pero sin limitarse a la residencia o estancia.

En realidad, el artículo 35 establece todo un proceso administrativo encaminado a decidir sobre la situación jurídica del extranjero menor que puede concretarse en la residencia legal, pero, sobre todo, en su repatriación, como ya se tuvo ocasión de comentar. La repatriación se configura así como el tratamiento administrativo que el legislador exige con carácter prioritario $y$, por eso, el artículo 35 concreta el procedimiento de actuación administrativo a través del cual se ejerce la potestad decisoria de repatriar a un extranjero localizado en nuestro territorio.

y ha exigido que sea estudiado en cada caso. Vid. por ejemplo, MoYA, D., "La intervención sobre los menores inmigrantes desamparados en Cataluña. Reflexiones desde la Constitución", Revista Migraciones, n. ${ }^{\circ} 12,2002$, p. 130 y ELÍAS MÉNDEZ, C. La protección del menor inmigrante desde una perspectiva constitucional, Valencia, 2002, p. 260. La lógica de este Memorandum no escapa a esta tentación y, aunque en la parte introductoria menciona el interés del menor y la necesidad de examinar cada caso, prima el objetivo de la repatriación por encima de todo, incluso de la finalidad reagrupadora con la familia que la Ley exige. 
La ubicación sistemática de la determinación de la edad dentro de este procedimiento no es casual ya que, de este modo, se la está configurando como una fase preliminar o previa dentro del procedimiento de repatriación del menor, en la medida que pretende confirmar su ámbito de aplicación subjetivo ${ }^{22}$. Así, la determinación de la edad y de otras circunstancias personales del indocumentado constituiría un acto de comprobación preliminar o de indagación informativa, preparatorio de la decisión administrativa final acerca de la repatriación.

La dogmática del Derecho administrativo define este tipo de actuación como acto administrativo de trámite. Esta calificación tiene relevantes consecuencias prácticas pues permite acudir al régimen general del procedimiento administrativo en este ámbito para suplir las numerosas lagunas legales, entre ellas las que se refieren al órgano competente y los recursos que caben contra la decisión ${ }^{23}$.

Si la determinación de la edad es un acto que está inmerso en un procedimiento administrativo de repatriación, entonces, parece adecuado pensar que la Administración ante la cual deben tener lugar los trámites sea la misma que aquella a la que compete el resto del procedimiento. Los conflictos de competencia que surgieron en torno a la repatriación de menores inmigrantes entre la Administración autonómica (en virtud de los asuntos de protección de menores del art. $148.1 .20^{\circ} \mathrm{CE}$ ) y la Administración del Estado (con base en asuntos de inmigración del art. $149.1 .2^{\circ} \mathrm{CE}$ ) intentaron aclararse mediante la Resolución de 11 de noviembre de 1998, por la

22 Molina Navarrete, C, "Artículo 35" en Comentario a la Ley y al Reglamento de Extranjería e Integración Social, Molina Navarrete, C. y Monereo Pérez, J.L., (dirs.), Granada, 2001, p. 547.

${ }^{23}$ La figura se contempla en todos los países de nuestro entorno cultural: GARCiATrevijano, J.A., La impugnación de los actos administrativos de trámite, Madrid, 1993 y GonzAlez Pérez, J., Manual de Procedimiento Administrativo, 2. ${ }^{a}$ Ed., Madrid, 2002, p. 202.

En cualquier caso, conviene referirse, siquiera brevemente, a aquellos actos que, aunque de un modo $u$ otro preparan el desarrollo de un procedimiento $o$ acto administrativo posterior, son distintos, al menos técnicamente, de los actos preparatorios. La doctrina italiana los define como actos-presupuesto, vid. por ejemlo, Sandulli, A.M., I/ procedimento amministrativo, Milano, 1959, p. 59. Esta categoría de actos se define en función de su singular autonomía, aunque con una esencial y concreta influencia, respecto del procedimiento o decisión administrativa de la que son presupuesto y cuyo objeto o sujeto tienden a individualizar. Con estas características se podria aceptar que la determinación de la edad fuera un acto presupuesto con vida jurídica, de alguna manera, independiente del procedimiento de repatriación ulterior. $Y$ posiblemente sea adecuado, lo que ocurre es que esta teoría reviste una mayor complejidad cuando se trata la impugnación directa o per se de estos actos autónomos, pues carecen de regulación expresa en España. De modo que la disciplina del acto de trámite garantiza, en nuestro ordenamiento, mayor seguridad jurídica. 
que se dictaron Instrucciones Generales sobre la Repatriación de Menores en Situación de Desamparo. En virtud del primer apartado de la Instrucción segunda y de la Instrucción quinta, la repatriación del menor debe ser acordada por el Delegado del Gobierno de la Comunidad Autónoma de que se trate, el Delegado del Gobierno en las Ciudades de Ceuta y Melilla o los Subdelegados del Gobierno cuando tuvieran competencia delegada para ello. En la actualidad, estas previsiones se encuentran dotadas de rango reglamentario, pues el artículo 62.4 párrafos $1 .^{\circ}$ y $4 .^{\circ}$ del RE las ha incorporado integramente ${ }^{24}$.

Con la atribución de la competencia para repatriar a la Administración periférica del Estado, sobre la base de su título competencial en materia de extranjería, se está enfatizando el carácter de control de flujos sancionador y policial que reviste, de forma inadecuada, la figura de la repatriación que, por propio mandato legal, debería tender a la realización del interés del menor y su reagrupación familiar.

Quizá por eso, el artículo 35 comienza con una alusión no muy afortunada a los Cuerpos y Fuerzas de Seguridad del Estado. A raíz de esta mención, la redacción del precepto da a entender que sólo cuando éstos localicen a un extranjero indocumentado, cuya minoría de edad no pueda ser establecida con seguridad, se podría poner en marcha la determinación de su edad como primera etapa antes de la repatriación. Hasta tal punto que, siendo la repatriación competencia exclusiva del Estado sólo podría actuar el Cuerpo Nacional de Policía y no, por ejemplo, la Policía Municipal25. En este sentido, basta con recordar el deber que tienen las Policías de las Comunidades Autónomas de velar por el cumplimiento de las Leyes del Estado en el territorio autonómico (artículo 38.2 de la Ley de Fuerzas y Cuerpos de Seguridad del Estado). Así como el deber de la Guardia Civil de cooperación recíproca y auxilio mutuo con el Cuerpo Nacional de Policía, a quien corresponden materialmente los asuntos de extranjería (art. 12.1 a), b), y c) de la misma Ley).

Con todo, la mayor objeción que se puede hacer en este asunto a la redacción legal es que no contempla que agentes no policiales actúen en este primer momento en que se debe determinar la edad. Con más razón cuando esta posibilidad parece más acorde con la realidad pues, a menudo, quien más contacto tiene con estos jóvenes son las personas encar-

24 Reglamento de ejecución de la LE aprobado por RD 864/2001, de 20 de julio.

${ }^{25}$ ARCE JiMÉNEZ, E., "Menores extranjeros", Revista de Extranjería, n. ${ }^{\circ} 4$, p. 9 en <www.reicaz.es/extranjeria/menu/deault.html> y Cabal, J.M., Comentarios a la Ley de Extranjería, Madrid, 2001, p. 262. 
gadas de los servicios de protección de menores de las Administraciones autonómicas, dado el menor grado de desconfianza que les genera ${ }^{26}$. Una cierta dosis de racionalidad del sistema exige que este tipo de problemas se resuelva de acuerdo con el principio de colaboración entre Administraciones Públicas (art. 103.1 CE y art. 3.1 y 2 de la Lèy de Régimen Jurídico de las Administraciones Públicas y del Procedimiento Administrativo Común, en adelante LRJAP) ${ }^{27}$.

Una cuestión interesante desde el punto de vista teórico, aunque con poca trascendencia real, consiste en saber cuáles son las posibilidades de actuación del extranjero que se sabe menor y quiere hacerlo valer con el fin de disfrutar del sistema que le brinda nuestro ordenamiento. Este aspecto adquiere relevancia desde la óptica del derecho a ser documentado que tiene cualquier menor, consagrado en el artículo $7 \mathrm{CDN}$, en íntima conexión con la identidad y la dignidad de la persona, así como con el desarrollo de su personalidad. Una de las facultades de este derecho constitucional del niño a ser documentado se refiere a la determinación de la edad, que podrá exigir como una potestad de su derecho subjetivo ${ }^{28}$. En la práctica, si esta situación se produjera va a ser canalizada a través de los servicios de protección de menores ya que éstos suelen ofrecer menos reticencias entre la población inmigrada que otros agentes $y$, no en vano, les representan en todas las actuaciones necesarias para su documentación (art. 63.12 RE).

Aún así, uno de los problemas competenciales más serios en torno a la determinación de la edad, es ocasionado por la intervención del Ministerio Fiscal, en principio indiscutible, dada la función de protección de menores que tiene encomendada. El artículo 35.1 exige que, cuando sea

${ }^{26}$ En este sentido, parecía más apropiada la redacción del precepto legal propuesta por el Grupo Parlamentario Catalán, porque en lugar de los Cuerpos y Fuerzas de Seguridad del Estado, aludía a la localización del presunto menor por cualquier servicio público. Enmienda Número 306 al Proyecto de Ley Orgánica de Reforma de la Ley Orgánica 4/2000, de 11 de enero, sobre Derechos y Libertades de los Extranjeros y su Integración Social, BOCD, VII Legislatura, Serie A, 18 de octubre de 2000, Núm. $12-5$, p. 117 y 118.

${ }^{27}$ Esta necesaria colaboración administrativa se percibió antes de la aprobación de la nueva Ley, como lo demuestra el Acuerdo de coordinación y compromiso para mejorar la respuesta institucional al problema social de la inmigración de menores y jóvenes indocumentados en situación de alto riesgo social suscrito el 9 de marzo de 1999, entre diversos organismos de la Generalidad de Cataluña, el Delegado del Gobierno, el Fiscal jefe del Tribunal Superior de Justicia de Cataluña y representantes municipales del Ayuntamiento de Barcelona y Santa Colma de Gramenet.

${ }^{28}$ Esteban de La Rosa, G., op. cit., p. 139. 
localizado un extranjero indocumentado cuya minoría de edad no pueda establecerse con seguridad, se ponga el hecho en conocimiento inmediato del Ministerio Fiscal, que dispondrá la determinación de la edad. El inconveniente se debe, no al hecho de la participación del Ministerio Fiscal en este trámite, sino al alcance que ésta ha de tener, ya que al no poder deducirse exclusivamente del tenor de la Ley, debe estar condicionada por el tipo de pruebas que deben practicarse para establecer la edad del inmigrante.

Así, como primera aproximación, el modo imperativo con el que el legislador contempla la participación del Ministerio Fiscal, al decir que dispondrá la determinación de la edad, apunta a que le está atribuyendo la obligación de disponer lo necesario, al margen de cualquier juicio de oportunidad, para instar la colaboración de otras instituciones (sobre todo médicos forenses e instituciones sanitarias) ${ }^{29}$. Esta redacción también permite excluir, de alguna manera, que el legislador haya querido atribuir la competencia para determinar la edad al Ministerio Fiscal pues, si así lo hubiera querido, habría bastado con decir que el Ministerio Fiscal determinará la edad y no, como ha hecho, dispondrá la determinación.

En cualquier caso, la intervención del Ministerio Fiscal sólo puede ser examinada a la luz los medios de prueba de la edad, que constituyen el eje sobre el que gira todo lo demás.

2. Las pruebas de determinación de la edad y los derechos fundamentales del extranjero indocumentado.

Junto con un grupo de medios de prueba que podemos denominar jurídicos, pues consisten en la consulta de datos personales en el Registro de Menores en situación legal de desamparo (art. $69.2 \mathrm{RE}$ ) $^{30}$ o en ciertas instituciones públicas o privadas, nacionales o extranjeras (art. 35.5 LE), existen otro tipo de pruebas de carácter médico más problemáticas. El

29 Instrucción 2/2001 FGE, cit., párr.9. También Adroher Biosca, S., "Régimen jurídico de los menores extranjeros no acompañados" en Seminario Europeo sobre Menores Extranjeros no Acompañados, Madrid, 31 de noviembre y 1 de diciembre de 2001, p. 209.

${ }^{30} \mathrm{EI}$ Registro se crea, justamente, con la finalidad de erradicar una práctica que se venía repitiendo, mediante la cual, los extranjeros menores se identificaban de forma distinta ante diferentes servicios de protección de menores, dilatando sucesivamente el trámite de su identificación y, con éste, su repatriación. Por eso, tal como previó el RE y aconseja la Circular FGE 3/2001 de 21 de diciembre, deberían constar en el Registro todos los datos que puedan facilitar las investigaciones previas a la repatriación. En concreto, el fichero se denomina ADEXTTRA y está regulado en la Orden 1751/2002, 20 de junio, por la que se regulan los ficheros informáticos de la Dirección General de Policía que contiene datos de carácter personal. 
legislador las tiene presentes en todo momento, como demuestra la petición de colaboración de las instituciones sanitarias.

Normalmente consisten en una peritación ósea de forma que, mediante el contraste de una radiografía de la mano o muñeca de la persona examinada con un modelo preestablecido, se obtiene como resultado un arco de edades posibles en función de los nudos de osificación y de la persistencia de cartílagos. El método que cuenta con más difusión se llama Greullich y Pyle, aunque también se utiliza otro muy similar denominado TannerWhitehouse ${ }^{31}$.

La determinación de la edad ósea presenta el problema de la fiabilidad, ya que adolece de un serio riesgo de sobreestimación o subestimación de la edad biológica. Esto se debe a que los estándares de comparación son antiguos y se realizaron para descubrir patologías relacionadas con el crecimiento $y$ otras finalidades distintas de las que se persiguen ahora. A lo que hay que añadir que se hicieron tomando como muestra población de raza blanca, normalmente de origen inglés o estadounidense y de familias acomodadas, cuando está demostrado que las malas condiciones de vida afectan al proceso de maduración ósea y que ésta no se produce a la misma velocidad en todas las razas ${ }^{32}$. Por esta razón, el arco de edades posibles ha de tomar en consideración, como mínimo, unos dieciocho meses de riesgo de sobreestimación de la edad $y$, de entre este arco de edades, habrá que estar siempre a la inferior, pues es lo que, en general, satisface el interés del menor.

Estos medios de prueba de la edad son los que permiten cuestionar ciertas intervenciones del Ministerio Fiscal en el procedimiento. En realidad, cuando se trate de meras comprobaciones jurídicas sólo cabe cuestionar la eficacia de la intervención del Misterio Fiscal disponiéndolas, pues se trata de actuaciones que puede llevar a cabo la policia por sí misma. En cambio, cuando estemos ante pruebas de carácter médico, la intervención

31 Para más información se puede consultar ACNUR, Informe sobre la Determinación de la Edad en España. Programa de Menores No Acompañados Solicitantes de Asilo, Madrid, 2002. También, VV.AA, "L'incidence de l'âge sur l'application de la loi penale et de l'ordonnce du 2 Novembre 1945 (entrée et sejour des estrangers France)", Journées Françaises de Radiologie.Session: Age osseux, 2002, en <http://www.sfip-radiopediatrie.org>.

En general se han descartado otros métodos de peritación ósea que exigen, por ejemplo, una radiografía de cadera y otros muchos más agresivos, como el que consiste en un examen del desarrollo genital de los niños inmigrantes, que recuerda Elías Méndez, C., op. cit., p.316.

32 Dutarte, P., Faut-il croire ...l'âge osseux?, que se puede consultar en <www.avre.org/articles/age_osseux.html>. 
del Ministerio Fiscal ha de ser examinada con más cuidado, si en su práctica pueden afectarse derechos fundamentales.

Ciertamente, las pruebas radiológicas, como los demás reconocimientos médicos que se han de efectuar por decisión de un poder público, constituyen intervenciones corporales susceptibles de afectar determinados derechos fundamentales, como el de integridad física o intimidad ${ }^{33}$. Esto significa que, para que la afectación del derecho sea constitucionalmente irreprochable, han de practicarse y acordarse revestidas de determinadas garantías.

En efecto, en la medida que un derecho fundamental pueda verse afectado, la actuación del Ministerio Fiscal puede plantear problemas de validez, debido a que tiene prohibida la adopción de cualquier medida limitativa de derechos fundamentales (art. 5, párr. 2. ${ }^{\circ}$ Estatuto Orgánico del Ministerio Fiscal, en adelante EOMF). Por eso, no podrá acordar la realización de las pruebas, pues su intervención sólo se puede defender en respuesta a la función tuitiva de los intereses del menor y de defensa de la legalidad que el ordenamiento le confiere. La cuestión no deja de cobrar importancia si recordamos que, durante la tramitación parlamentaria del precepto, se defendió esta redacción alegando la agilidad en los trámites que iba a suponer la participación del Ministerio Público en el procedimiento ${ }^{34}$.

Entre las garantías que constitucionalmente cabe exigir en la realización de las pruebas que permitan deducir la edad, hay que citar que deben

${ }^{33}$ El problema de las intervenciones corporales y los derechos fundamentales ha sido objeto de especial atención por la doctrina procesalista penal. Esta doctrina, salvando las distancias entre la sede del derecho procesal penal y los procedimientos administrativos de extranjería, se puede aplicar en nuestro estudio. Al respecto se puede consultar: DiAz CABIALE. J.A., "Cacheos superficiales, intervenciones corporales y cuerpo humano como objeto de recogida de muestras para análisis periciales" en Medidas restrictivas de los derechos fundamentales, Cuadernos de Derecho Judicial, Madrid, 1996; FERRER AMIGO G., "Incidencia constitucional de las intervenciones corporales" en La restricción de los derechos fundamentales de las personas en el proceso penal, Cuadernos de Derecho Judicial, Madrid, 1993; GIL HERnández; A., Intervenciones Corporales y derechos fundamentales, Madrid, 1995; MONER MUÑOZ, E., "Las intervenciones corporales" en La restricción....cit; Sáez RODRíguez, J., «Papel del juzgado de guardia ante determinadas actuaciones médicas que pueden afectar a los derechos fundamentales: cacheos, reconocimientos médicos y toma de muestras. Solicitud de autorización judicial para determinadas actuaciones facultativas" en Actuaciones del Juzgado de Guardia en relación con los derechos fundamentales, Madrid, 2000 o VIDAL FUEYO, C., Intervenciones corporales, derechos fundamentales $y$ proceso penal (pendiente de publicación).

${ }^{34}$ Así lo defendió el Grupo parlamentario catalán en la citada Enmienda 306, que en este extremo coincidía con la postura que el Grupo Popular sostuvo durante la tramitación de la Ley 4/2000 en el Senado. BOCG, Senado, VI Legislatura, Serie B, 19 de noviembre de 1999, Núm. 330-3, p. 22-23. 
ser practicadas por un profesional con la pericia necesaria, no suponer un grave riesgo para la salud y, como no podía ser de otro modo, ser proporcionadas $^{35}$. En general, se ha' contemplado que sean autorizadas judicialmente.

\section{La autorización judicial de las pruebas para determinar la edad.}

La autorización judicial de estas pruebas constituye una garantía esencial de respeto de los derechos fundamentales pues, en nuestro modelo constitucional, se atribuye a los jueces la condición de garantes ordinarios de los derechos de las personas ${ }^{36}$.

En el plano constitucional, está justificada la idoneidad de la intervención del juez en garantía de derechos, frente a actuaciones administrativas que puedan suponer una situación de riesgo específico de vulneración de dichos derechos ${ }^{37}$. Sin embargo, cuando la Constitución se refiere a la función garantizadora de derechos de los Jueces en el artículo 117.4 CE, exige una ley expresa que se la atribuya, que no existe en nuestro ordenamiento jurídico. No obstante, parece que esta falta de previsión legal puede superarse.

En realidad, el artículo 117.4 CE es una norma que habilita al legislador para que atribuya a los jueces las funciones de garantía de derechos que estime más convenientes. A pesar de la libertad del legislador, se puede considerar que la Constitución fija unos parámetros en relación con ciertos sujetos y situaciones a proteger. En concreto, impone singulares deberes a los poderes públicos para la garantía de los derechos de los menores (art. 39, 49 y $9.2 \mathrm{CE}$ ). De esta forma, se podrían deducir algunos criterios que, más allá de la voluntad política, penetrarían en el campo de los deberes jurídicos de los poderes públicos y, por ello, deberían ser tenidos en cuenta por el legislador a la hora de atribuir funciones de garantía de sus derechos. Cuando el legislador no los desarrolle de forma explícita, como ocurre con la autorización judicial de las pruebas de determinación de la edad, la previsión se podría inferir y aplicar directamente de la

35 Por todas, STC 207/1996, de 16 de diciembre. Sobre la proporcionalidad, Barnes, J, «El principio de proporcionalidad: estudio preliminar», Cuadernos de Derecho Público, n. ${ }^{\circ}$ 5, 1998 y Medina Guerrero, M., «El principio de proporcionalidad y el legislador de los derechos fundamentales", en Idem.

36 Rubio Llorente, F, La forma del poder, Madrid, 1993, p.369 a 380 . De igual modo, entre otras, STC 115/1987, de 7 de julio, Fdto. Jco. $10^{\circ}$ y STC 215/1994, Fdto. Jco. $3^{\circ}$

37 SÁNCHEZ BARILAO, J.F.; Las funciones no jurisdiccionales de los jueces en garantía de derechos, Madrid, 2002, p. 172. 
Constitución. El deber de protección del interés del menor ampara, entonces, la interpretación del principio de intervención judicial como principio constitucional ${ }^{38}$.

La intervención judicial constituye una garantía para los derechos de los menores extranjeros, pero esta función garantizadora no sería, en sentido estricto, una tarea jurisdiccional (art. 117. $1 \mathrm{CE}$ ). Esta actuación judicial se encuadra más bien en el ámbito de administración de justicia (art. 117. 4 CE) a modo de colaboración con otros poderes del Estado ${ }^{39}$, destacadamente, en el procedimiento que nos ocupa, la Administración del Estado. Se trataría así de la participación de un juez en una función administrativa, como colaboración entre poderes, de forma que la determinación de la edad se mantiene como acto de trámite dentro de un procedimiento administrativo, para cuya formación se exigiría la colaboración judicial (no jurisdiccional) de un juez en garantía de derechos.

Aún más, la falta de regulación genera problemas relacionados con el órgano judicial que ha de autorizar la peritación ósea y el cauce procedimental que ha de seguirse.

Si hacemos memoria, en la redacción del precepto antes de su reforma, se atribuía a los Juzgados de Menores la determinación de la identidad

${ }^{38}$ Entre otros, SÁNCHEZ BARILAO, J.F., Las funciones...op,cit, p. 192, también, MARTiN Morales, R., El principio constitucional de la intervención indiciaria, MARTín MORALES, R. (coord.), Granada, 2000, p. 27.

Afirmar que el principio de intervención judicial es un principio constitucional significa entender constitucionalizada, de forma implícita, la exigencia de la autorización judicial en las limitaciones de derechos fundamentales. La constitucionalización sería implícita porque, de forma expresa, sólo se exige para ciertos derechos como la inviolabilidad del domicilio, el secreto de las comunicaciones y la libertad de expresión e información. Para todos los demás, entre los que se incluyen los derechos afectados en la determinación de la edad, integridad física e intimidad, se entiende que, implícitamente la Constitución quiso reservar su limitación a los jueces y que, por tanto, existe en la Constitución una reserva jurisdiccional absoluta para la limitación de cualquier derecho.

Aunque no se puede dejar de mencionar que algunos autores defienden que, fuera de los casos consignados al juez expresamente por la Constitución, la ley podría atribuir a otro órgano su limitación, si bien se suele requerir que concurran las circunstancias de urgencia y necesidad. Vid., por ejemplo, Ortells Ramos, M., «Exclusividad jurisdiccional para la restricción de derechos fundaméntales y ámbitos vedados a la injerencia constitucional" en Medidas restrictivas...op.cit., 1996; o GIMENo SENDRA, V., El Nuevo Proceso Penal, obra colectiva, Valencia, 1989, p. 84. También la STC 207/1996, 16 de diciembre, Fdto. Jco. $4^{\circ}$.

39 «El interés por administrar justicia - art. 117.1 CE- estriba en la posibilidad constitucional de incluir dentro de ella, además de la potestad jurisdiccional - art. 117.3las funciones no jurisdiccionales atribuibles por ley a Jueces y Magistrados en garantía de derechos - art. 117.4, in fine CE-" SÁNCHEZ BARILAO, J.F., Las funciones...op. cit., p. 65. 
y la edad de los extranjeros indocumentados. La regulación fue duramente criticada debido a que su intervención criminalizaba la sola presencia de los extranjeros indocumentados en España, pues la actividad del Juez de Menores se ha desenvuelto en el conocimiento de hechos tipificados como delito y el extranjero indocumentado no incurre en ninguno, todo lo más, en una infracción administrativa (art. 96 y 97 de la Ley Orgánica del Poder Judicial, en adelante LOPJ y 2 de la Ley de Responsabilidad Penal del Menor, LRPM) ${ }^{40}$. Por otra parte, la Ley $4 / 2000$ antes de ser reformada, al atribuir la competencia de determinación de la edad a los Juzgados de Menores, les estaba asignando una competencia no prevista en la LOPJ ${ }^{41}$. En la actualidad, no tiene sentido hablar de la intervención de este órgano judicial, al carecer de la cobertura legal específica e individualizada que han de tener cada una de sus atribuciones, debido a su excepcionalidad y especialidad $^{42}$. No obstante se ha apuntado, aunque con ciertos recelos, la conveniencia de la intervención de un Juez de Instrucción ${ }^{43}$.

A falta de regulación expresa, se han de aplicar las normas generales de atribución de competencia. Así, por razón de la materia, las actuaciones para conocer la edad pueden englobarse dentro de los asuntos de protección de menores porque, en último término, la finalidad de la determinación de la edad es que la Administración confirme la minoría de edad, para poder decidir sobre su repatriación, según el interés del menor exija en cada caso. En efecto, los Juzgados de Primera Instancia son los competentes en materia de protección de menores (art. 172. 6 y 158.3 del CC, en conexión con el art. 779 de la Ley de Enjuiciamiento Civil) ${ }^{44}$. Así lo confirma la cláusula de competencia residual del artículo 85.1 LOPJ, según la cual los Juzgados de Primera Instancia son compe-

40 Así lo puso de manifiesto el Grupo Parlamentario Catalán en su Enmienda 306, cit. En este sentido, Campuzano Díaz, B., "Los menores en el Derecho de extranjería" en W.AA., Extranjeros en España: régimen jurídico, Sánchez-Roda Navarro, C. (coord.), Murcia, 2002, p. 361.

41 Sobrón Ostos, F., "La protección del menor en el proceso penal" en Actuaciones del Juzgado de Guardia en relación con los Derechos Fundamentales en Estudios Jurídicos. Cuerpo de Secretarios Judiciales, vol. I, 2000, p. 208.

42 Aparicio Blanco, P., "Diligencias de instrucción restrictivas de derechos fundamentales: competencia del Juez de Menores en el ámbito de la Ley de Responsabilidad Penal de Menores", Revista de Poder Judicial, n. ${ }^{\circ} 60,2000$, p. 60.

43 Calatayud, E., "Menores Extranjeros no Acompañados», Seminario Europeo sobre Menores Extranjeros no Acompañados, Madrid, 30 de noviembre $y 1$ de diciembre de 2001, p. 198 y 199.

44 En este sentido, Fábrega Ruiz, C.F., op. cit, p. 122 y Fano Navarro, M. J., «La situación del menor inmigrante bajo la tutela de las Entidades Públicas Españolas de Protección de Menores» en <www.uv.es>. 
tentes para conocer de todos aquellos asuntos que no sean asignados a otros juzgados dentro del orden civil. La Sección concreta que debería asumir esta tarea dependerá de la forma de distribución de competencias que se hubiera acordado en cada caso (art. 98 LOPJ) pero, en los lugares en que existan como secciones especializadas, los Juzgados de Familia se ocuparán de este tipo de autorizaciones.

No se puede descartar que, cuando la ley regule de forma expresa la autorización judicial para este tipo de pruebas, se la atribuya a los Jueces de lo Contencioso-Administrativo, como es lógico, tratándose de una autorización judicial previa para realizar un acto administrativo limitativo de derechos en el curso de un procedimiento administrativo. Esta misma exigencia cabe reiterarla respecto a la autorización de otra limitación de un derecho fundamental en el curso de un procedimiento administrativo de extranjería: la autorización judicial para el internamiento de extranjeros con un procedimiento de expulsión en curso (art. 58.5, 60 y $62 \mathrm{LE})^{45}$.

En cuanto al problema del cauce procedimental, diremos que, dada la singular naturaleza de la función judicial no jurisdiccional y, en cierta manera, no contradictoria, la tramitación más adecuada es la jurisdicción voluntaria, prevista todavía en la antigua Ley de Enjuiciamiento Civil de $1881^{46}$, además de ser el único cauce que nuestro ordenamiento permite ante la falta de regulación expresa ${ }^{47}$. Por otra parte, la jurisdicción voluntaria es considerada por la mayor parte de la doctrina una actividad cuasi-adminis-

45 Vidal Fueyo C., Constitución op. cit..., p. 235. También Peces Morate, E., "Garantías jurisdiccionales para los extranjeros", Reflexiones obre la Nueva Ley de Extranjeria, Cuadernos de Derecho Judicial, Madrid, 2001, p. 234. No obstante, se podría afirmar que seguiría suponiendo un problema para la tutela judicial, pues estos órganos jurisdiccionales pueden tardar en dictar sentencia. En estos casos, se ha apuntado la posibilidad de establecer un órgano administrativo o cuasi-judicial para una decisión rápida sobre la legalidad de las decisiones administrativas en materia de extranjería (expulsiones o prohibiciones de entrada, por ejemplo), y que ya existen en la mayoría de paises europeos. Vid. Díz, L y RolG, E., "Las garantías de los derechos de los inmigrantes" en VV.AA, La nueva regulación de la inmigración en España, Aja, E.(coord.), Valencia, 2000, p. 203. Además, se demanda la creación, en su caso, de juzgados de guardia de lo contencioso-administrativo, RoIG, E., Constitución e Inmigración: La constitucionalización del Derecho de extranjería en España, (pendiente de publicación), p.159.

46 Libro III de Ley de Enjuiciamiento Civil aprobada por Real Decreto de 3 de febrero de 1881. Se mantiene vigente hasta que entre en vigor una nueva Ley sobre Jurisdicción Voluntaria, tal como dispone la Disposición Derogatoria Única.1.1 ${ }^{\text {a }}$ de la Ley de Enjuiciamiento Civil, Ley 1/2000, de 7 de enero.

${ }^{47}$ En este sentido, Barja de Quiroga, "El consentimiento y la esterilización de los incapaces", Cuadernos de Política Criminalm, n. ${ }^{\circ} 44,1991$, p. 345 y 346, y ALMAGRo NoSETE, J. Derecho Procesal: Proceso Civil. Tomo I, vol.II, Valencia, 1999, p. 385. 
trativa y esto la convierte en especialmente idónea para la autorización judicial de las pruebas de edad, que también es función administrativa ${ }^{48}$.

\section{Sobre el papel del Ministerio Fiscal en el procedimiento para determinar la edad.}

Los problemas que plantea la intervención del Ministerio Fiscal se refieren al tipo de actuación que se le encomienda y no a su presencia, pues ésta es necesaria siempre tratándose de menores, de presuntos menores, sin representante legal. Excluida la autorización de las pruebas, su actuación en el procedimiento debe adecuarse a la concepción constitucional del Ministerio Fiscal como garante de los derechos fundamentales, que se concreta en una función tuitiva en defensa de los menores frente a todos, en especial frente a la Administración y a los Jueces (art. 124.1 CE y art. 3. 7 EOMF).

En este sentido, no se puede olvidar la función de vigilancia de la actividad administrativa en asuntos de protección de menores (art. $174 \mathrm{CC}$ y la propia LPJM), así como otras actuaciones que el ordenamiento atribuye a los Fiscales, por ejemplo, en relación con la libertad personal, están legitimados para interponer habeas corpus. En el ámbito de protección de menores, es relevante el listado de derechos que la LPJM reconoce a los menores previendo, en la mayoría de los casos, la intervención del Fiscal en su defensa. En este contexto son importantes las facultades relacionadas con la asunción de la tutela de menores en desamparo, donde ha de desempeñar una nada desdeñable labor.

De manera más general, el Código Civil reconoce al Fiscal amplias posibilidades de actuación en la adopción de medidas para evitar peligros al menor o apartarle de perjuicios, pudiendo para ello solicitar todas las medidas que estime oportunas al juez (art. 158. $4 \mathrm{CC}$ ).

Así pues, el ordenamiento permite delimitar, con cierta amplitud, las facultades que corresponden al Ministerio Fiscal en el transcurso de las actuaciones de la determinación de la edad del extranjero indocumentado, en defensa de quien se sospecha que puede ser menor de edad. Sin embargo, no es tan fácil delimitar los instrumentos o mecanismos proce-

\footnotetext{
${ }^{48}$ Ya que, cuando en los actos de jurisdicción voluntaria se produce la garantía de los derechos individuales, se está cumpliendo el interés general que es propio de la actividad administrativa. Vid. por ejemplo, GÓmeZ FERRER SAPINAA, R., «Jurisdicción voluntaria y función notarial», Revista Juridica del Notariado, n. ${ }^{\circ} 1$ Extraordinario, 1992, p. 46.
} 
sales a los que pueda o tenga que acudir el Ministerio Fiscal. Se critica esta práctica legislativa bastante habitual que consiste en establecer la intervención del Fiscal pero sin preocuparse por indicar los mecanismos procesales para canalizar esa intervención ${ }^{49}$. En esta ocasión, la solución más apropiada debe darse en el caso concreto y dependerá del derecho o interés que motiva su actuación y de la autoridad ante quien actúa.

\section{LA DETERMINACIÓN DE LA EDADY LA LIBERTAD PERSONAL.}

\section{La privación de libertad policial.}

La libertad personal resulta afectada durante las actuaciones de determinación de la edad. Desde el momento en que las Fuerzas y Cuerpos de Seguridad del Estado localizan a un extranjero, de cuya minoría de edad se duda, hasta que la edad es determinada con certeza, transcurre un lapso de tiempo en el que el extranjero requerido carece de la facultad de autodeterminación de su conducta. Por eso se encuentra, desde la óptica jurídico-constitucional, en una situación de privación de libertad.

En un primer momento, cuando la policía pide al extranjero la documentación y, además de no lograr identificarle, duda sobre su minoría de edad, le requerirá que le acompañe a las dependencias más próximas en las que sea posible su identificación. Nos encontramos en el ámbito de la privación de libertad policial, también llamada retención policial, por ser ante esta autoridad ante quien transcurre ${ }^{50}$. Esta figura está regulada en el artículo 20.2 de la Ley de Seguridad Ciudadana, que fue objeto de una interpretación conforme al artículo 17 de la norma fundamental en la STC $341 / 1993^{51}$.

Así, durante la fase de las indagaciones policiales, la persona afectada goza de todas las garantías previstas en el ordenamiento para esta singular privación de libertad. Esto significa, por ejemplo, que aunque la Ley de Extranjería guarde absoluto silencio al respecto, cabe plantear un habeas

49 Moral Garcia, A. del, "Derechos humanos, menores y Ministerio Fiscal», La Ley, 1998, vol. VI, p. 2220.

${ }^{50}$ Asi fue reconocido por la Fiscalía General del Estado en la Instrucción 2/2001, cit.

51 Desde el primer momento se constató que esta medida de retención afectaba, sobre todo, a extranjeros. Un interesante comentario sobre los criterios policiales para llevar a cabo la identificación y el principio de no discriminación por raza vid., SÁNCHEZ BARILAO, J.F., "Identificación documental de nacionales y extranjeros. (Comentario a la STC 13/2001, de 29 de enero)", Revista Española de Derecho Constitucional, n. ${ }^{\circ} 64$, 2002,p. 217 y ss. 
corpus cuando el afectado piense que ha sido privado de libertad ilegalmente ${ }^{52}$. $\mathrm{O}$ que, en cualquier caso, la retención en dependencias policiales no puede durar más del tiempo imprescindible, con un límite máximo de 24 horas, de acuerdo con el propio artículo 17.2 de la Constitución, en conexión con el artículo 17 de la LRPM ${ }^{53}$.

Además, tendrá derecho a la asistencia de un intérprete si la persona retenida en dependencias policiales no habla o no comprende el castellano, pues sólo así podrá conocer los motivos de su privación de libertad, tal como exige el artículo $17.3 \mathrm{CE}^{54}$. Por el contrario, no parece exigible el derecho a la asistencia letrada, pues de acuerdo con el mismo artículo constitucional ésta sólo es preceptiva en los términos que las leyes establezcan, que: la han restringido a las diligencias policiales de declaración y reconocimientos de identidad del detenido (detenido en sentido de detención preventiva del artículo $17 \mathrm{CE}$ ). Y las diligencias de identificación de una persona indocumentada no constituyen un supuesto de detención preventiva.

Aunque la asistencia letrada no se contemple como una de las garantías que la jurisdicción constitucional ha reclamado de la retención policial, no se puede decir que el menor esté desasistido jurídicamente, pues la presencia del Ministerio Fiscal, que tiene conocimiento de los hechos desde el primer momento, le asegura esta ayuda.

\section{La privación de libertad judicializada.}

Cuando las diligencias que puede llevar a cabo la policía resulten infructuosas, porque no han permitido identificar $y$ averiguar la edad del: indocumentado, es necesario practicar una peritación ósea. En este caso, la permanencia en dependencias judiciales deja de estar justificada, pues el reconocimiento médico ha de practicarse en una institución sanitaria por personal técnico adecuado ${ }^{55}$. A partir de este momento, aunque el

52 Art. 117.4 CE, como reconoce la STC 341/1993, de 18 de noviembre.

${ }^{53} \mathrm{Al}$ respecto, APARICIO BLANCO, P., "La detención u otras medidas de coerción de: menores", Revista de Derecho Penal, n. ${ }^{\circ} 111,2001$.

54 Instrucción 2/2001, cit. A la misma conclusión llega, desde una interpretación analógica del art. 520.2 e) de la Ley de Enjuiciamiento Criminal, que regula los derechos dell detenido, TOMÉ GARCíA, J.A., "Las diligencias de identificación en dependencias policiales: del art. 20.2 de la Ley Orgánica sobre la Protección de la Seguridad Ciudadana», p.759.

55 Sin auxilio del INSALUD y su correspondiente en las Comunidades Autónomas no se podrían practicar estas pruebas, pues es habitual que las instalaciones de los servicios médicos forenses carezcan de aparatos de rayos X. FÁBREGA RUIZ, C.F., La protección... op. cit., nota 179, p. 121. 
menor siga estando custodiado de hecho por la policía, la situación ha dejado de ser una privación de libertad policial pues se ha debido producir la intervención de un juez. Cuando la autoridad judicial se haya pronunciado sobre la autorización de las pruebas médicas, ha consentido, indirectamente, la situación de privación de libertad de quien, con su visto bueno, va a ser conducido a un centro médico para someterse a las pruebas radiológicas oportunas. La consecuencia más importante que podemos deducir afecta a la posibilidad de interponer un habeas corpus, ya que, a diferencia de lo que ocurre durante la retención policial, ahora la situación de privación de libertad es conocida y consentida, si quiera de forma indirecta, por un juez.

Aunque existe un evidente interés en que la determinación de la edad del extranjero indocumentado se realice sin la menor dilación, no siempre será posible realizarlo con la rapidez necesaria, porque haya que contrastar las pruebas practicadas, repetirlas o por cualquier otro motivo. Cuando esto suceda, no se puede prolongar de forma indefinida la permanencia en el centro médico $y$, mucho menos, en dependencias policiales del presunto menor. En estas ocasiones normalmente son trasladados a los centros de menores tutelados, en los cuales se está empezando a crear unidades de primera acogida, para evitar los trastornos que plantea que ingresen en ellos, aunque sea por poco tiempo, personas que pueden ser mayores ${ }^{56}$. Como centros que funcionan, generalmente, en régimen abierto, presentan evidentes facilidades para la huída de los jóvenes antes de que se logre conocer su edad y decidir sobre su régimen juridico.

En efecto, para garantizar que el presunto menor no se fugue, prolongando con ello el círculo de indocumentación-retención, se debe acordar su internamiento. El internamiento en el centro es una medida cautelar para evitar la fuga del menor y garantizar, bien la sanción de expulsión si al final resulta mayor, o bien, lo que es más importante ahora, la protección adecuada si se confirma que es menor. El problema es que la LE, cuando se refiere al procedimiento de determinación de la edad, no contempla esta medida. Tratándose de una medida cautelar limitativa de dere-

56 Estas Unidades de Primera Acogida suplen la carencia de centros específicos donde llevar a las personas sin documentos mientras se averigua su edad. Esta falta de centros adecuados es denunciada por GutiérRez DíAZ, M". ${ }^{a}$., "EI Menor Extranjero", La Responsabilidad Penal de los Menores, Estudios Jurídicos del Ministerio Fiscal, vol. I, Madrid, 2001, p.379 y ss. y por ARCE JIMÉNEZ, E., op. cit, p. 9. De la misma manera el Defensor del Menor de la Comunidad de Madrid ha señalado la necesidad de que existan centros específicos para estos menores (o presuntos menores), en Menores Inmigrantes en España, Madrid, 2001, p. 48. 
chos debe ser acordada judicialmente, aplicándose por analogía la figura del internamiento en un centro de educación especial, que cabe dentro de las amplias potestades que el artículo $158.3 \mathrm{del}$ CC confiere al juez para que, a instancia de parte o de oficio, adopte las medidas necesarias para la protección del menor en cualquier procedimiento, incluso de jurisdicción voluntaria ${ }^{57}$. De nuevo, como la medida se encuadra en el ámbito de la protección de menores, el órgano judicial competente es el Juez de Primera Instancia.

Finalmente, hay que reconocer que se impone una regulación más adecuada de todas estas actuaciones, en especial, en lo que se refiere a. las intervenciones judiciales. Como se ha podido deducir, en un periodo. de tiempo relativamente corto, ha de intervenir un Juez de Primera; Instancia autorizando las pruebas médicas necesarias para poder averi-. guar la edad y, quizá, el mismo juez, deba intervenir poco después acordando el internamiento de la misma persona en un centro de menores. Pero, además, puede que el Juez de Instrucción tenga que pronunciarse: sobre un eventual recurso de habeas corpus que se le plantee (art. 3 de la Ley de Habeas Corpus y art. 17.6 de la LRPM).

En realidad, hay un denominador común a todas estas intervencio-. nes judiciales, pues en todas ellas el juez debe examinar una actuación de: la Administración, cuando pide las pruebas médicas, cuando solicita un internamiento o al privar de libertad a una persona indocumentada. Por esta razón, sería deseable que lege ferenda se atribuya el conocimiento de todas estas actuaciones a un mismo órgano judicial, el Juez de lo Contencioso Administrativo, que es a quien en nuestro ordenamiento le: corresponde el control de la actuación administrativa ${ }^{58}$.

57 En Cataluña, para evitar esta analogía con el internamiento en centro de educación especial, se ha previsto el internamiento reeducativo, como una de las formas de: ejercicio de la tutela administrativa, mediante la Ley $8 / 2002$, de 27 de mayo, sobre: Medidas de Protección de los Menores Desamparados y de regulación de la Atención Especial de los Adolescentes conConductas de Alto Riesgo Social. Un comentario sobre! los problemas de constitucionalidad y de falta de garantías que plantea la Ley puede! verse en, MoYA, D., "La intervención sobre los menores inmigrantes desamparados en! Cataluña. Reflexiones desde la Constitución", Revista Migraciones, n. ${ }^{\circ}$ 12, 2002.

58 Como antecedente cabe citar lo que ocurrió con la autorización de la entrada $y$. registro en domicilio que primero se atribuyó a los Jueces de Instrucción para encomendársela ahora a los Juzgados de lo Contencioso-Administrativo (art. 91.2 LOPJ y 8.5 de Ley de la Jurisdicción Contencioso Administrativa). Aunque PECES MORATE, E., "Garantías...", op. cit., p. 234 cree que el cambio de criterio en el caso del juez competente para autorizar entradas y registros en domicilio se debió, más que a argumentos de lógica jurídica, a los inconvenientes que estaban creando a la Administración las resoluciones de aquellos Jueces. Vid. nota 45. 


\section{LOS RECURSOS CONTRA LA DETERMINACIÓN DE LA EDAD.}

En ningún momento se puede olvidar, ni la trascendencia que tiene la determinación de la mayoría de edad del extranjero, ni la falta de fiabilidad que, en ocasiones, presenta la estimación de la edad a través de la peritación ósea. En este sentido, se suele reclamar la posibilidad de adecuar los márgenes de error a las nuevas circunstancias y de practicar de nuevo las mismas pruebas transcurrido algún tiempo después ${ }^{59}$. Desde la perspectiva jurídica, esta posibilidad se articula a través del derecho de recurso contra la estimación de la edad que ha efectuado la Administración, basándose en el informe médico de las instituciones sanitarias ${ }^{60}$.

Como ocurre con otras cuestiones la Ley de Extranjería y el Reglamento guardan silencio. Tras la lectura de estas normas no se sabe si, una vez determinada la edad, es susceptible de recurso, ni qué recurso cabe, ni contra quién debe interponerse.

Es ahora cuando la calificación de la determinación como acto de trámite adquiere una especial relevancia pues, para suplir esta laguna, permite acudir al régimen general de recursos que las normas administrativas prevén para los actos de trámite. En concreto, la Ley 30/1992 de Régimen Jurídico de las Administraciones Públicas $y$ del Procedimiento Administrativo Común, modificada por la Ley 4/1999, en adelante LRJAP, y la Ley de la Jurisdicción-Contencioso-Administrativa, en adelante LJCA. A ella se remite con carácter general el art. 21.1 LE y, de forma expresa, la Disposición Adicional Segunda del RE.

59 En Francia, el Consejo de Estado ha estimado que los métodos de determinación de la edad ósea no pueden ser considerados, a primera vista, como fiables y sin riesgo de error, por eso anuló una decisión de la autoridad administrativa en la que se denegaba un permiso de estancia a un extranjero que decía ser menor porque las pruebas de edad, las únicas en base a las que adoptó la decisión, declaraban que tenía diecinueve años (Arrêt du 28 décembre 1998). Sin embargo, ante la falta de regulación expresa de la determinación de la edad en este país, la práctica judicial presenta diferencias. En cualquier caso, la Sala Civil de la Corte de Casación acepta esta diferente valoración de la peritación ósea, pues la considera como un medio de prueba sujeto al principio de libre valoración judicial (Arrêt de 13 de noviembre de 2001). Así mismo, la Comisión Suiza de Recurso en materia de asilo ha llegado a la conclusión de que los resultados de las pruebas óseas no pueden aportar una prueba fiable de la edad del interesado (Decisión de 12 de septiembre de 2000). Sobre estos casos, vid. Ferré, N., "La détermination de la minorité", Plein Droit, n. ${ }^{\circ}$ 52, 2002.

${ }^{60}$ Debe constatarse que, en el fondo, la Administración no tiene demasiado margen de discrecionalidad a la hora de apreciar la edad de los extranjeros indocumentados. Dado que las pruebas médicas no suelen ofrecer nunca una edad exacta sino que siempre fijan una horquilla más o menos amplia de edades probables, habrá que presumir que su edad es la establecida como límite inferior en dicha horquilla, Instrucción 2/2001 FGE, cit. 
La norma general es la irrecurribilidad de los actos de trámite, pero se admiten excepciones cuando ha decidido directa o indirectamente el fondo del asunto, ha supuesto para el afectado la imposibilidad de continuar con el procedimiento o ha producido indefensión o perjuicio irreparable (art. 107.1 JRJAP y art. 25.1 LJCA, en relación con el derecho a la tutela judicial efectiva del art. $24 \mathrm{CE}$ ).

De esta forma, cuando la Administración, a la luz de los informes técnicos, se convence de que el extranjero sin documentos es, efectivamente, menor de edad, no nos encontramos ante ninguno de estos supuestos ya que, en general, no se ha producido un perjuicio irreparable $y$, por otra parte, el procedimiento de repatriación continúa de acuerdo con los trámites habituales, según lo que requiera el interés del menor. En este caso, habría que concluir que el acto es irrecurrible, sin perjuicio de que, en un ulterior recurso sobre la decisión de repatriación, se alegue lo que se estime conveniente en relación con la edad y otras circunstancias personales ${ }^{61}$.

Bien distinto es el caso contrario, cuando la Administración, basándose en las pruebas practicadas que obran en el expediente, llegue a la conclusión de que el extranjero no puede ser considerado menor de edad. Así, al considerarlo mayor, la Administración pondría fin al procedimiento de repatriación para incoar, con toda probabilidad, un procedimiento de expulsión preferente (63.1 y art. 53 a) LE en la redacción de la Ley 14/2003). Si es así, como la estimación de la mayoría de edad impide al afectado continuar con el procedimiento de repatriación, cabe defender la posibilidad de recurrirla ${ }^{62}$.

$61 \mathrm{Ni}$ la LE, ni en el RE, ni siquiera en la Resolución interministerial por la que se dictan Instrucciones Generales sobre la Repatriación de Menores, se refieren a las eventuales impugnaciones de las decisiones de repatriación. La FGE, en su Circular 3/2001, IV, 5, ha interpretado que las decisiones de la Administración periférica del Estado sobre repatriación son recurribles de acuerdo con las normas y trámites del procedimiento administrativo y de la jurisdicción contencioso-administrativa. A diferencia de otras ocasiones en las que la FGE se ha ocupado de problemas similares, la FGE no ha descendido a indicar aspectos procesales concretos.

62 En todo caso es necesario adoptar una interpretación restrictiva del concepto. de procedimiento y vía administrativa, con GARCíA-TREVIJANO, J.A., La impugnación de los: actos de trámite, Madrid, 1993, p. 131.

Esto es, si interpretamos de forma amplia estos conceptos, como insinúa el art. 25. $1 \mathrm{LJCA}$, deberiamos esperar a la decisión que resolviera el procedimiento de expulsión que, casi con total seguridad, se abriría, una vez descartada la repatriación por tratarse de un adulto, pues sólo así se habría culminado la vía administrativa. La solución por la que se opta es, desde luego, más beneficiosa para un extranjero que pretende demostrar su minoría de edad en una segunda instancia. 
Antes de hacer un breve comentario sobre los recursos que, en su caso, cabe interponer contra una estimación de la edad que se cree errónea, conviene advertir que, normalmente, no existirá un acto expreso con constancia escrita, sino que habrá de presumirse tácito de acuerdo con los actos concluyentes de la Administración, como puede ser la mera incoación de un expediente de expulsión ${ }^{63}$.

El régimen general en materia de recursos que resultaría aplicable a la determinación de la edad sería, entonces, el régimen de recurribilidad de los actos de trámite y no debería verse alterado cuando no existiera acto expreso, al margen de las dificultades que acarrea esta circunstancia.

En cuanto a los recursos administrativos hay que excluir el recurso administrativo ordinario de alzada del art. 114 LRJAP pues, como ya se ha dicho, cuando se le considera mayor de edad, se pone fin a la vía administrativa, en el sentido de imposibilitar la continuación con el procedimiento de repatriación. Por otra parte, de la Disposición Adicional Sexta RE se puede inferir una regla que confirmaría este extremo. Según parece, las resoluciones que, como las relativas a la repatriación, dicten los Delegados del Gobierno y Subdelegados del Gobierno en materia de extranjería, como norma general, ponen fin a la vía administrativa. Lo mismo cabe decir de la determinación de la edad, en la medida que es imputable al órgano que conoce del resto del procedimiento de repatriación.

Siendo asi que, la única posibilidad que la normativa permite, se reduce a la interposición potestativa de un recurso de reposición, para que, el mismo órgano a quién se le imputa la decisión, tenga la oportunidad de volver a examinar el caso (art. 116 LRJAP). Este órgano será siempre, en lo que atañe a la determinación de la edad, el Delegado del Gobierno; incluso en los casos en los que hubiera delegado los asuntos de repatriación de menores a los Subdelegados del Gobierno porque, en este último caso, como la estimación de la edad sería una decisión adoptada en el ejercicio de una competencia delegada se reputa dictado por el órgano delegante (art. 13 LRJAP). Hay que recordar que este recurso que permite a la Administración volver a pronunciarse sobre los mismos hechos, tiene un carácter potestativo, puede interponerse o, por el contrario, puede acudirse directamente al orden jurisdiccional contencioso-administrativo ${ }^{64}$.

63 La falta de formalización de la actuación de la Administración es uno de los aspectos que suscita más críticas en la práctica administrativa de la extranjería. Por ejemplo, RoIG, E., Constitución... op.cit, p. 206.

64 Hay que dejar constancia de una interesante propuesta que pretende superar el problema que, en general, afecta al Derecho de extranjería en relación con los recursos de los actos administrativos. Se trata de la potenciación del recurso administrativo 
Sin embargo, la alternativa al recurso jurisdiccional no es muy alentadora. Los recursos contenciosos plantean problemas de efectividad de la tutela judicial, que comienzan con las dudas sobre el órgano jurisdiccional! competente ${ }^{65}$.

Las dudas se deben, en definitiva, a que la LJCA omite de forma escandalosa una regulación específica de los asuntos de extranjería. Por eso, se debe acudir a la confusa regulación de los recursos contra actuaciones de la: Administración periférica del Estado, que es la competente en la materia. En concreto, hay que acudir a la cláusula residual del artículo 10.1 j) de la LJCA que atribuye a las Salas de lo Contencioso-Administrativo de los Tribunales Superiores de Justicia el conocimiento de las actuaciones administrativas no asignadas expresamente a otros órganos de este orden ${ }^{66}$.

Está solución no es, desde luego, demasiado satisfactoria en el ámbito de la extranjería, porque dificulta el acceso a la tutela judicial de quien pretende que se estudie en una segunda instancia la determinación de su edad. La razón estriba en que, este órgano judicial, se suele encontrar geográficamente más alejado y puede tardar más en dictar sentencia que, por ejemplo, los Juzgados de lo Contencioso-Administrativo.

Además, a la falta de formalización de ciertas actuaciones administrativas y a la inseguridad respecto del órgano competente para interponer el recurso, hay que sumarle que la legitimación de las asociaciones de inmigrantes, que en la práctica son quienes mejor pueden articular su defensa en juicio, parece excluirse en el art. 31.1 LRJAP y 19.1 b) LJCA. Aún más, el principio según el cual la interposición de un recurso administrativo o contencioso no suspende la ejecución del acto recurrido, condiciona, en el caso del recurso contra una estimación errónea de la edad, toda la efectividad de la tutela al momento de adopción de medidas cautelares (art. 111 LRJAP y art. 130 LJCA).

de acuerdo con la vía abierta por el art. 107.2 de la LRJAP. En él se prevé la posibilidad de que los recursos administrativos sean resueltos por un órgano colegiado no sometido a instrucciones jurídicas, de carácter específico, participado no sólo por juristas sino por expertos en cuestiones de fondo (asistentes sociales entre ellos). La apertura de estos órganos a las ONG significaría un incremento importante del grado de protección de los extranjeros en sede administrativa. Vid. RoIG, E., Constitución...op. cit, p.178.

65 Sobre este problema, Pıcó LoREnzo, C., «Problemas de tutela judicial efectiva en el ámbito de la extranjería", Jueces para la Democracia, $n .{ }^{\circ} 37,2000$, p. 14 y ss. y Nieto Martín, F., "Procedimiento preferente de expulsión de extranjeros", Jueces para la Democracia, n. ${ }^{\circ} 41,2001$, p. 26.

${ }^{66}$ Esta tesis es asumida por el Tribunal Supremo, Auto de la Sección Primera de 20 de octubre de 2000 . 
En cualquier caso, el extranjero es titular del derecho a la asistencia jurídica gratuita porque, aunque la LE lo limita cuando se trata de extranjeros en situación de irregularidad, la reconoce en los procedimientos administrativos y judiciales que puedan llevar a la expulsión y, como ya se ha indicado en varias ocasiones, la determinación de la mayoría de edad conduce de forma casi inexorable a la expulsión ${ }^{67}$.

Las trabas para la efectividad de la tutela judicial no son sino una manifestación de la quiebra del respeto a los derechos humanos y a los principios de legalidad y seguridad juridica, que se produce como consecuencia de la deficiente regulación que hace la Ley respecto a la determinación de la edad de los extranjeros. Con este trabajo, sólo se ha pretendido colaborar, en la medida de lo posible, en la extensión constitucional de los derechos fundamentales dentro de un Estado de Derecho, en el que estén suficientemente garantizados los derechos de todos, también de los extranjeros, de los menores extranjeros $y$, como no podía ser de otro modo, de los menores extranjeros indocumentados.

64 Aragón Reyes, M., considera inconstitucional la exclusión del derecho a la asistencia jurídica de los extranjeros en situación irregular en procedimientos que no conduzcan a la expulsión o devolución en "¿Es constitucional la nueva Ley de Extranjería?», Claves de la Razón Práctica, n. ${ }^{\circ} 112,2001$, p.16. EITC ha confirmado recientemente esta tesis, pues en la STC 95/2003, de 22 de mayo, declara la inconstitucionalidad parcial del art. 2 a) de la Ley de Asistencia Jurídica Gratuita, que excluía del ámbito de aplicación de este derecho a los extranjeros que residian en España de forma ilegal, por vulnerar el derecho a la tutela judicial efectiva. Sobre esta sentencia, Lucas, J. de, "La difícil igualdad (A propósito de una reciente sentencia del Tribunal Constitucional)", en Derecho Migratorio y Extranjería, n. ${ }^{\circ}$ 3, julio, 2003, p. 209 y ss. 